\title{
Teaching students with visual impairments in an inclusive educational setting: a case from Nepal
}

\author{
Kamal Lamichhane
}

Associate professor

Center for Research on International Cooperation in Educational Development (CRICED), University of Tsukuba, Japan

Tel: +81-29853-7285

Fax: +81-29853-7288

e-mail: kamal@criced.tsukuba.ac.jp

Dr. Kamal Lamichhane is an associate professor at the center for research on international cooperation in educational development (CRICED) of the University of Tsukuba in Japan. Besides focusing on human capital formation, he also studies the association of disability and poverty with the particular focus on low and middle income countries aiming at promoting disability inclusive sustainable development. 


\title{
Teaching students with visual impairments in an inclusive educational setting: a case from Nepal
}

\author{
Using the dataset from teachers and students and utilizing both qualitative and \\ quantitative techniques for analysis, I discuss teaching style considerations in \\ Nepal's mainstream schools for students with visual impairments. Results of the \\ econometric analysis show that teachers' years of schooling, teaching experience \\ and using blackboard were positively correlated to teaching style adjustment \\ whereas negative correlation of their age indicated that younger teachers are \\ more likely to adjust their teaching styles for disabled students. Additionally, in \\ the descriptive analysis of particular teaching style considerations implemented \\ by teachers, explaining more; more interactions; simultaneously reading out \\ while writing on the board; placing students with visual impairments in the front \\ bench with other academically sound students were reported as some of the basic \\ pedagogical adjustments made in the classroom. Providing disability specific \\ training programs for teachers, making arrangements of sufficient educational \\ materials and support provisions are suggested as some of the implications \\ toward improving teaching in mainstream classroom through which quality, \\ equality and inclusion in education could be achieved.
}

Keywords: Inclusive education; Teaching style considerations; Students with visual impairments; Teachers; Nepal

\section{Introduction}

Amid ongoing global discussions about what kind of education is most appropriate, in the 1970s, UNESCO recommended that developing countries implement inclusive education as a cost-effective alternative to educate children with disabilities. As a result, the interest over inclusive education has been growing (Lamichhane 2015; Mittler 2000). In the latest Incheon declaration of world education forum in South Korea in 2015, paragraph seven clearly recognizes the inclusion and equity in education of people with disabilities (UNESCO, 2015). Likewise, the recent post-2015 sustainable development goals have also clearly incorporated inclusion of disability in education goal (UN, 2015). 
Despite these commitments and progress in international level, universal and inclusive education of people with disabilities is yet to be achieved especially in low income countries. Although collective and constructive efforts from all stakeholders of the community is required Toward promoting and successfully implementing inclusive education, in most of the developing countries, simply placing students with disabilities into mainstream classes together with their peers without disabilities constitutes its implementation (Lamichhane 2015).

One of the crucial issues regarding access and continuity in inclusive and quality education for people with disabilities is whether mainstream school teachers are able to meet the individual needs of these students. When there are students with disabilities in mainstream classes, teachers need to make reasonable adjustments to accommodate the individual educational needs of these students.

In this context, using a mixed methods approach which includes the dataset and focus group interviews from seven mainstream schools of Nepal, this paper discusses the education of students with visual impairments in an inclusive educational setting and seeks to answer the following questions: What teaching style adjustments are made by teachers while teaching students with visual impairments in the same mainstream class? What characteristics of teachers are correlated in their teaching style adjustment and what difficulties do students face while learning in inclusive educational setting?

Previous to 1964, Nepalese with visual impairments had no access to education, as there were no schools either in special or inclusive settings that could accommodate their individual needs (Lamichhane 2013). Since 1964, students with visual impairments have been studying together with their peers without disabilities in an integrated educational setting (Hall 1990). One of the main innovations of Nepal's education program is the introduction of skill-based classes for students with visual 
impairments, prior to their placement in mainstream classes (Lamichhane 2010).

Students with visual impairments remain in these resource classes until they gain such necessary skills as the use of braille, Independent Living Skills (ILS), and Orientation and Mobility (O\&M). These are directly related with the Expanded Core Curriculum (ECC) which refers to the nine areas of instruction that children and youths with visual impairments require to be successful in school, the community, as well as the workplace (Sapp and Hatlen 2010). The nine areas of ECC includes skills such as compensatory or access, career education, independent living skills, O\&M, recreational and leisure skills, self-determination skills, social interaction skills, use of assistive technology, and sensory efficiency skills. after the acquisition of some of these skills, they begin to attend mainstream classes in Nepal. Once these students enter mainstream classes, they no longer attend resource classes unless they encounter specific problems related to their impairment, including academic issues (Lamichhane, 2010). As a part of promoting inclusive education, Nepal government has changed its previous units such as special education or special needs education into inclusive education division. Moreover, regardless of disability, age six is prescribed to enroll in the primary education of grade 1 . Rest of the paper is organized as follows: section 2 includes literature review; section 3 discusses the dataset and techniques for analysis; section 4 presents results; Discussion of the results is presented in section 5; finally, section 6 presents concluding remarks.

\section{Literature review}

UNESCO (1994) identified important attributes for inclusive education, such as the need for inclusive schools to respond to the diverse needs of students, accommodate both different styles and rates of learning, ensure quality education to all students with appropriate curricula, organizational arrangements, teaching strategies, resource use and 
partnerships with their communities. Recognizing these as important attributes, clearly, teachers are considered as one of the central components to implement inclusive education (Haskell 2000). Regardless of disability status, effective teaching styles maximize students’ learning potential (Lamichhane, 2015(.

On the other hand, ample literatures have discussed the challenges of teaching students with disabilities in mainstream classes for example Elder et al. (2015) for Kenya, Unianu (2012) for Romania, focusing on physical, autistic disorders and Down syndrome, Berry (2008) for USA on attitude on disability in general, Subban (2005) for Australia on mainstream teachers. With the case from Australia, O'Donoghue \& Chalmers (2000) discussed the issue of teachers' classroom work management when they are placed in the position of having a student with a severe or profound intellectual disability. Acknowledging the difficulty of teachers to teach students with different type of disabilities in inclusive classroom in Turkey, Coskun et al. (2009) emphasized on the requirement of educational materials. Likewise, studies such as (Heiman 2001; Minke, Bear, Deemer, and Griffin 1996) also state the difficulty for teachers to implement inclusive education due to the inadequate resources. Similarly, with the review of the literatures for different countries, a study by (Scott, Vitale, Marston 1998) argue that teachers lack the necessary knowledge and skills to work with students with disabilities in inclusive educational setting.

The aforementioned studies have mainly focused on teachers' attitude but little is known about how teachers do adjustment and what factors are associated for the teaching style adjustment decisions when they teach students with disabilities, in this case those with visual impairments in inclusive educational setting, especially in low income countries. Therefore, by this empirical study, I intend to partially fill the existing knowledge gap aiming at facilitating further dialogues on providing conducive 
educational environment for these students. As research begins to emerge on inclusive education in developing countries, studies like this will be an important contribution in effectively implementing inclusive and quality education for persons with visual impairments.

\section{Dataset}

The study design is based on mixed method. Mixed method is defined as a research approach focusing on research questions that call for real-life contextual understandings and multi-level perspectives (Johnson, Onwuegbuzie, \& Turner, 2007). Acknowledging that every methods has its own limitation (Patton 2015 page 316) states that there is a need of multiple methods to be used for triangulating both methods as well as data.

First, the author did a quantitative survey and analysis explained through a qualitative follow up interviews with students. The reason of employing mixed method is to draw on the strengths of each. Quantitative technique helps to gather descriptive information and then to examine relationships among variables on teachers' decision on teaching style consideration. These variables are measured and yield numeric data that can be analyzed statistically to provide evidence to help establish probability of certain factors playing a vital role on teachers. Also, it can create the possibility of replication, generalization and comparison. Similarly, the purpose of using qualitative technique is to gain a depth of understanding of the effectiveness and challenges in classroom learning via students through their quotes. In terms of merging data, the author presents results of both quantitative and qualitative analysis and discuss them in the discussion section. Interpretation of the results consist of both quantitative analysis and qualitative interviews that built on each other and thus contribute to the objective of this research. The author began the study keeping in mind both a deductive and an inductive approach. 
The survey data and the interview data were well suited respectively to deductive and inductive approach.

\subsection{Survey participants}

Teachers teaching in mainstream schools were the participants for this survey. To approach the respondents, the author selected seven schools of four different districts of Nepal in which students with visual impairments were studying. Three schools in Chitwan district, the Central part of Nepal, one each in Kapilbastu and Palpa district and two in Kaski district, the Western part of Nepal were selected. The size of the students in these schools ranged from 1000 to 1500 . There were approximately 200 students with visual impairments, studying in these schools. All of these schools were major schools in the respective districts, offering education program for students with visual impairments. These schools considered those who are blind, partially sighted, or have low vision as students with visual impairments who were subject to receive facilities of learning Braille and staying in dormitories. Therefore, in this study, the definition of students with visual impairments is in line with these schools. In Nepal, all the public schools are required to follow same curriculum that includes subjects such as Nepali language, mathematics, science, social study, English language and population and environment and as they study in the mainstream schools, students with visual impairments have to study the same subjects unlike with their peers without visual impairments.

Surveys were administered to all teachers who were present on the survey administrated days and who were teaching from grade six and above as students with visual impairments were found studying in these grades. Total teachers surveyed were 122. However, sixteen teachers did not provide the complete information and they were excluded from the analysis. 
The survey was conducted in six-week sessions from January to February of 2011. Completion of the survey required longer time as the author had to move from one school to another within the district and one district to another. Due to some holidays, the author had to visit some schools twice. To obtain the information from the participants, questionnaires were administered. The survey covered a wide variety of socioeconomic information including teachers' demographic characteristics, educational background, and information on teaching experiences and trainings together with the question on whether they change their teaching style or not if there are students with visual impairments in the classes. Additionally, for those stating that they adjust their teaching styles were also asked with an open-ended question, what kind of changes they make to accommodate these students.

Table 1. Students and Teachers information

Table 1 shows the information on students and teachers from column 2 to 5. More specifically, column 2 and 3 gives information respectively for students without and with visual impairments for each of the schools whereas column 4 and 5 presents combined information respectively for students with visual impairments and teachers. In total, 113 students with and 2909 without visual impairments were used in this study where the total percentage of students with visual impairments stand as 3.7 percent. Similarly, the valid response rate is 86.9 percent for teachers.

\subsection{Participants for focus group discussion}

Additionally, to further capture challenges experienced by students with visual impairments in the classroom teaching, focus group discussion was undertaken with the students from grade 5 to 10 in September, 2014. 20 students participated the discussion. 
The discussion held in the resource class of the school, lasted for 2 hours. Discussion was conducted in Nepali and was recorded digitally and later translated into English. The school was located in Dadhing district which is nearly 30 KMs away from Kathmandu. Approximately, 800 students were studying in the school whereas about 30 were with visual impairments. Since there were support system in place for these students, the author considered those students who were registered or accepted in schools as with visual impairments. None of our students we selected had duel or multiple impairments. Some of the questions asked in the focus group discussion were: Do teachers help when you experience difficulty to catch up the lesson? What particular difficulties you experience while studying in the mainstream classes? What kind of educational materials are provided to you? Are the textbooks available in Braille? What is your most difficult subject and why? Do you learn from friends without disabilities when you do not understand any lesson?

Following repeated re-reading of the transcripts, excerpts from the transcripts have been put into a matrix as unit analysis, condensed into meaning units and then coded. This process has allowed the author to utilize the key contents of the data and reveal themes relevant to the participants' experience within the transcripts (Graneheim and Lundman, 2004). Assimilation and interpretation of the main themes have formed the basis of the final paper. Excerpts from the transcripts were interpreted and presented in subsection 4.3.

\subsection{Reliability}

To maintain the reliability of the study, measures such as appropriate standardization of interview procedures and pre-testing of the survey questions were adopted to enhance its internal validity or credibility. The prolonged engagement in analysing the data further assures the credibility of the themes. Since the interview was conducted in 
Nepali language — the mother tongue of both the author and participants - the full contents and cultural context of their meaning is well-captured.

\subsection{Ethical consideration}

The study was carried out with informed consent from the participants, who were aware that they could withdraw from the study at any time, without incurring any personal consequences. Participants were informed that their participation in the study is entirely voluntary, and they may refuse to answer any questions they do not wish to answer. They were also assured that the survey and interview will be confidential, never use individual data, the information gathered from all participants will be analyzed as a group, and used only for purpose of this study. Moreover, a requesting letter from the graduate school of economics of the University of Tokyo was submitted to each of the school administrations for their approval of conducting the study with the participants.

\subsection{Technique for quantitative data analysis}

Binary logistic regression model was employed for analyzing the factors associated with teachers' teaching style adjustment decision. Similarly, to understand actual teaching style considerations made by teachers, they are presented descriptively in percentage points. While coding teachers' responses on teaching style considerations, those freely written answers were read by the author and generated nine categories. As these categories are derived from the open-ended question, some participants wrote more than one adjustment they make and thus the responses were greater than the total number of respondents. In total, 143 responses were available for 106 teachers which are explained in table 4. 


\subsection{Model and variables for econometric analysis}

Dependent variable used here is related to whether teachers do adjustment in their teaching styles while teaching students with visual impairments in the same mainstream class. Dependent variable is operationalized as binary logistic, i.e., 1 if a teacher does adjustment in his/her teaching style, 0 otherwise.

By this analysis, the author aims to estimate the probability of teachers' decision to change teaching style based on observed values of the explanatory variables. Logistic regression establishes a functional relationship between the binary response (teaching style changing or not changing) and other different factors that are recognized as playing a role in doing that decision. To estimate this logistic equation, age, years of schooling, experience of teaching and sex. of teacher and region specific variable, marital status, preparation hours of class, use of black or whiteboard and teaching of technical subjects such as: math and science are used as explanatory variables. Detail definition of variables is shown in table 1.

Table 2. Definition of variable

\section{Results}

This section presents the results on teachers' characteristics correlated to their teaching style adjustment decision for students with visual impairments in inclusive educational setting. Table 3 shows the basic characteristics of the participants. teachers. Among 106 teachers, more than two third (76 percent) found doing some kind of changes in their teaching style to accommodate student with visual impairments. Majority of them (74 percent) were from rural area. Vast majority (86 percent) were married and 77 percent were male. The lowest age of the teacher was of 18 and the highest was 59 years. Mean 
age of them was 40.82 years. Teaching experience was ranged from minimum zero years to maximum 39 years with average being 18.35 years. Similarly, teachers in average allocated 3.62 hours of their daily time to prepare for the lesson. Furthermore, 40 percent teachers taught in higher grade of 8 to 10. Additionally, 76 percent teachers stated that they always use black board. In average, 18 and 14 percent teachers taught maths and science as a main subject.

Table 3. Descriptive statistics

Results on factors correlated to teachers' teaching style adjustment decision are presented in table 4 . Results show the negative correlation of teachers from rural areas at 5 percent and their age to the probability of making teaching style adjustment decision at 10 percent significance level indicating that teachers from rural areas and with old age are lesslikely to change their teaching style. Furthermore, teachers' years of schooling at 5 percent, experience of teaching and always using black or white board are positively correlated at 10 percent significance level. Black or white board is a simple chalk or marker board as used in traditional classrooms. Finally, compared to their female counterparts, male teachers have significantly positive correlation to the teaching style adjustment decision at 1 percent significance level.

Table 4. Logistic estimation for teacher`s decision to change teaching style 


\subsection{Descriptive analysis of teaching style considerations}

This section presents specific teaching style considerations made by teachers while teaching students with visual impairments in mainstream class. The intention is to identify particular considerations of those teachers who stated the change in their teaching style.

Table 5 shows that among the categories, explaining the subject matter more is the major consideration made by teachers. 40.57 percent of the total respondents reported that they make efforts to elaborate subject with the special focus to students with visual impairments. 26.42 percent reported that they make more interaction in the classroom to increase the active participation of these students. Similarly, giving students with visual impairments special attention is another consideration reported by 21.70 percent teachers. Going near to students, individually teaching them if they don't understand, teaching in slow pace, showing the real objects so far that is possible etc were included in this category.

Additionally, 14.15 percent teachers stated that they ask help of students without disabilities to support their friends with visual impairments, particularly for reading the book, explaining pictures and reading out what is written on the black or white board. Moreover, considering that students with visual impairments require longer time to write in Braille, 10.38 percent teachers stated that they provide enough time for them while taking notes. As a part of reasonable accommodation, considering that students with disabilities require more time to appear in exams, department of education of Nepal government has made provisions of additional time for students of all disability categories if they face barriers to write answers in the exams by themselves. Rule 47 in chapter 9 has stipulated special provisions for STUDENTS WITH DISABILITIES. This provision was made with third amendment of the Act in 2005 stating clearly that in case if students could not attempt the questions within the prescribed time limit, the 
superintendent may provide additional time of maximum one hour and thirty minutes (Department of education, 2002). While visiting the schools and interviewing students, it was observed that this rule has been effectively implemented for school and national level exams. For the very reason, similar provisions have been implemented in Japan. In Japanese Universities, 1.5 hours additional time is provided to students with visual impairments no matter whether they use Braille or other alternatives such as computer to appear in exams (author's direct experience and personal communication with University administrators). Furthermore, for those with visual impairments, to follow the class without knowing what teachers have written on the board is indeed difficult. To overcome this problem, only 7.55 percent teachers reported simultaneous reading aloud what they write on the board as a part of their considerations.

In addition to aforementioned 6 categories, placing students with visual impairments on front bench, placing them with academically sound and helpful students without visual impairments and giving priority to oral methods are last remaining three teaching style considerations made by these teachers which may have significant implications on implementing inclusive education. The percentage decreased by 35 percent for last three categories compared to the first category.

Table 5. Teaching style adjustment by teachers

\subsection{Descriptive analysis of teaching style considerations}

In the focus group discussion among students, questions about educational materials available to them and difficulties they experience for the subject matters were discussed. As reported in the previous section, in mainstream classes, students with visual 
impairments are generally taught by the same subject teachers who were found having no training or teaching experience for students with visual impairments.

In terms of difficulties experienced, regardless of any grades, all students stated mathematics, particularly geometry, and science subjects difficult to learn in the mainstream class. Mainstream teachers are unable to pay particular attention to explain picture-based problems to them ddue to other large number of students without disabilities as well as due to not having both the techniques and the technology to deal with. "Teacher often draws pictures on the board and I need to ask with my friend who seats nearby me.” one student in grade 9 said. For each of the section of the grade, together with 2 or 3 visually impaired, around 40 students without visual impairments were found studing together, making it difficult for a teacher to pay special attention with individual education plans.

According to these students, the lack of support and facilities was also a problem. however, often these interviewees indicated that they were able to continue with the help of friends. One interviewee said, "Teachers were not aware of how to teach with students with visual impairments. They often used the blackboard for subjects like science, mathematics and even English.” The same interviewee stated that due to the support of nondisabled friends, he was able to catch up the lessons. Similar cases were reported by Lamichhane (2013( for Nepal to those with visual impairments.

Additionally, students also felt difficult to learn some of the contents in the subjects such as social studies and geography for the same reason that they were not properly taught about pictures. Likewise, due to the unavailability of dictionary in Braille, students of grade 9 and 10 shared difficulties to learn english as a second language. "If dictionary is available in Braille, we could understand the meaning of each 
words and could do less mistakes in the spelling of the word” said by the student in grade 10.

In terms of educational materials, though students were given slates, styluses, it was found that there was only a Perkins Brailler for resource teachers in the school. Furthermore, the school had no computer facilities available through which resource teacher in charge of students with visual impairments could prepare materials including questions for exam into Braille. The school was found requesting one of the NGOs on visual impairment located in Kathmandu to transcribe the questions for the exams into Braille.

Additionally, though students with visual impairments were offered education in an inclusive educational setting, there were yet no any policy to provide opportunity for them to take exams in Braille, particularly for higher grades for example beyond 8. "We have to make answers orally after being read the exam questions by an assistant, who would then transcribe the answers on the exam sheet.” A student in grade 8 Said.

The results from interviews indicate that although each of the students have diverse educational needs, in school environments where these needs cannot be addressed, students with visual impairments may face challenges in receiving quality education in an inclusive educational environment.

\section{Discussion}

This section discusses the results of regression analysis followed by descriptive findings and students' interviews. In the regression analysis in table 4, the negative correlation of teachers' age to teaching style adjustment decision can be connected with the assumption that teachers in young age are more flexible and enthusiastic, less rigid and more dynamic in teaching. Also, why younger teachers have more probability to change teaching style might be attributed to the fact that they have more years to spend in 
teaching profession than old ones and thus they do not want to be criticized by their students with visual impairments. In contrast, older teachers maybe rigid to change their teaching style possibly because it requires additional time, techniques and enthusiasm which they may not be able to manage compared to younger teachers. Though no previous studies explored directly this issue, in terms of teachers' attitude, studies such as (Cornoldi et al. 1998) and (Lampropoulou and Padelliadu 1997) respectively in Italy and Greece discussed that older teachers appear to foster less positive attitudes than younger teachers toward educating students with disabilities in an inclusive setting. Another qualitative study in Tanzania also found that newly qualified teachers were implementing different teaching techniques while teaching students with disabilities (Westbrook and Croft, 2015).

Moreover, the positive correlation of teachers' longer years of schooling and teaching experience are consistent with the casual observation that more educated teachers have more opportunity to increase knowledge on teaching skills and techniques. Additionally, teachers with longer years of schooling may develop positive attitude on teaching style adjustments so that they can facilitate students' participation in the classroom activities. Again referring the case from Tanzania, more experienced teachers were aware of inclusive teaching strategies noticeably compared to teachers in other countries such as Ghana, Kenya, Mali and Senegal (Westbrook and Croft, 2015). At the same time, though age and experience are interrelated, it is not necessarily mean that just older are always more experienced. While not rejecting the possible connection of experience and older age, it should be noted that those who enter teaching job in older age obviously have less experience than those who enter in younger age. In this study, the negative effect of teachers' age and the positive impact of their experience can partially support this interpretation. 
Regarding the positive correlation of male teachers for teaching style adjustment decisions to accommodate the learning needs of students with visual impairments, given the local situation that women relatively experience gender discrimination (Lee, 2014) and less participation in labor market (Lamichhane, 2012), the author hypothesized that female teachers make teaching style adjustments. However, the result presented here does not support this argument. In terms of having positive attitude on inclusive education, previous studies have also mixed findings with regard to female and male teachers. A study on those with hearing impairments with the case of Greece discussed that male teachers held more positive views about inclusive education (Lampropoulou and Padelliadu 1997). However, other studies support the view that there is no correlation between a teacher's gender and their attitude toward inclusive education (Avramidis et al. 2000) for south-west England and (Van Reusen et al. 2001) for Texas in USA. Though these literatures are not directly associated with visual impairment, not from the low income countries like Nepal and perception differs based on country and culture specific context, further research with large scale surveys of teachers is required to clearly identify if any difference exist in teaching students with disabilities based on teachers' gender status.

Furthermore, the negative correlation of teachers from rural areas to their teaching style adjustment decision maybe consistent with the casual observation that availability of more opportunities and a possibility of access to latest information in urban areas may encourage them to make teaching style adjustments. Likewise, the positive correlation of Teachers using black or white board on their teaching style adjustment decision is consistent to the fact that if teachers do not change their teaching style while using board, students with visual impairments cannot see what is being written in the board. In opposite, those who never or sometimes use the board generally 
perform their classroom activities with methods such as oral explanation which may not be problematic for these students to grasp.

Additionally, in the result of descriptive analysis shown in table 5, in terms of using demonstration skills such as using black or white board, drawing pictures, and teaching geometrical configurations, teachers were found not employing any specific method of teaching except reading out what is written on the board. Among teachers who often used board, only small percentage of them were found simultaneously reading aloud while writing on the board: this can cause problem for the students to follow up the teachers. This is one of the plausible reasons why all students regardless of any grades in focus group discussion commonly shared the difficulty to learn these subjects in the mainstream class. (Lamichhane 2013) who studied the barriers to education for people with hearing, physical and visual impairments of Nepal stated the unawareness of mainstream school teachers on how to teach students with disabilities. He further stated that the lack of any special support inside the mainstream classroom for students with visual impairments held them back in education. In this context, the situation of some students with visual impairments to get support from their friends without disabilities can be regarded encouraging and positive but cannot be used to justify the successful implementation of inclusive education. Rather, it might be due to the consequences such as teachers being not able to pay sufficient attention on these students.

As a part of their teaching style consideration, for example, though their study did not directly deal with students with visual impairments but disability in general, (Westbrook and Croft, 2015) In Tanzania, found that teaching the same lesson several times as well as doing revision at the beginning of a new lesson as to give a second chance for those who were not able to understand in the previous class were done by 
some teachers. The same study reported the use of real objects by teachers as teaching and learning aids.

Together with placing them in the front bench, one of the descriptive findings presented in our study that is teachers' encouragement to students with visual impairments to consult with their friends without visual impairments indicates that there are still not any specific provisions for helping subject teachers in mainstream schools to meet the learning needs of these students. Students in our focus group discussion also mentioned the difficulty to learn subjects such as mathematics and sciences in part resulting from mainstream teachers largely using boards to draw the pictures and geometrical configurations. "I have to often rely on my friends who seat nearby me when teachers use black board.” Poor availability of educational materials reflected in the focus group discussion is consistent with the findings of the study by (Lamichhane 2010). His study discussed the status of education of children with visual impairments in Nepal through the survey and interviews with resource teachers and highlighted the need of equipping schools with educational materials such as textbooks in Braille and providing computer facilities. On the other hand, global monitoring report of UNESCO (2014) also, emphasized that teachers need support to teach children with disabilities and others who are disadvantaged in schooling. Similarly, (Adeyemi, 2009; Pryor et al., 2012) stated that Teachers' lack of training and knowledge to deal with heterogeneous groups along with poor material were barriers.

Clearly, unfamiliarity of mainstream teachers on the needs of students with visual impairments and failure to offer sufficient educational materials may negatively affect the notion of inclusiveness of these students. Though teachers have opportunity to receive general teacher training programs, this study did not find the availability of programs offered to them with respect to training how to teach students with visual 
impairments. Whatsoever teaching adjustments reported in this study by these teachers are thus not the direct outcome of special training they were provided, rather these adjustments are based on their own experience. In other word, lack of teaching materials and teacher training on disability have limited teachers' teaching style considerations to their own experience.

\section{Conclusion}

With the empirical study from Nepal, in this paper, I discussed the teaching style adjustments of teachers teaching students with visual impairments in the inclusive educational setting. The econometric analysis indicated that teachers' years of schooling and teaching experience are positively correlated to the decision to adjust their teaching style in order to accommodate the needs of students with visual impairments: as longer the years of schooling and teaching experience, greater the probability of teachers changing their teaching style. Also, those who always use black or white board were statistically significant to make adjustments in their teaching styles. Teachers’ age and coming from rural area were negatively correlated to their teaching style adjustment decision.

Furthermore, in the descriptive analysis, teachers reported nine different considerations as a part of their particular teaching style adjustment while teaching students with visual impairments. Some teachers were found making adjustments such as placing students with visual impairments in the front bench and also placing them with other academically sound students without disabilities while others were found to do more on pedagogical adjustments such as more interactions and telling verbally while writing on the blackboard.

Despite teachers making some adjustments in their teaching style, there are still many unresolved questions on whether these adjustments are sufficient and appropriate. 
For students with visual impairments as reflected in their focus group discussion results, beside the difficulty to learn about picture-based contents, appearing in the class test, and doing class works may pose difficulties whereas for teachers, checking students' assignment is a challenge as they cannot read it in Braille. Despite the increased inclusion of students with disabilities in mainstream schools, provisions for helping teachers to the possible arrival of them are yet to be developed. In absence of teaching skills, materials and training programs on diversed needs of students, both teachers and students with visual impairments in inclusive education are increasingly faced with the challenge. However, despite not getting any disability specific trainings, teachers were found doing several adjustments in their teaching which indicate that teachers are welcoming students with disabilities in the mainstream class. Our study presents an example of what mainstream teachers have been doing that is inclusive in nature, despite little input on inclusion within teacher education and curriculum development.

Therefore, as Nepal has ratified the UN Convention on the Rights of Persons with Disabilities (CRPD) in 2010, it should act upon providing quality education with the arrangement of adequate materials and support provisions as stated in the article 24 of the convention. Ongoing school sector reform program (SSRP) should also focus on these children. since general training programs offered to these mainstream teachers have not included training to enhance their skills to teach in inclusive classrooms, disability specific components can be added in ongoing general training programs. Such training program should include pedagogical aspect such as teaching techniques, technology and materials development and knowledge on disability so that teachers later can teach them with individual education plans. Additionally, Universities can design educational programs within their curriculum and offer it under the faculty of education so that all students willing to be a teacher will have opportunity to take course 
on disability and education. Experts on disability studies and education can greatly involve for designing these courses.

Finally, emphasizing on equality and quality in education but often connecting education of children with disabilities with cost effectiveness and not being able to provide conducive environment generally disregarding their additional needs would be a double standard. In the name of resource-poor environment, equality and quality of education for children with disabilities should not be sidelined.

A valuable next step would be to conduct further research on the challenges experienced by students with various type of disabilities learning in the mainstream schools and comparing their outcomes focusing on exam scores relative to a control group of students without disabilities. Additionally, as a part of considering the needs of students with visual impairments, some teachers were found placing students with visual impairments on front bench and with academically sound and helpful students without visual impairments which can actually help them to catch up the lessons. Moreover, these strategies can be regarded crucial toward promoting inclusionary practise in the classroom. However, it is necessary to conduct further studies to see the impact of these efforts on the performance of students with visual impairments particularly in exam scores.

Studies like this will shed light on a very important issue in inclusive education and help countries like Nepal develop policies toward providing universal and quality education for all.

\section{Acknowledgements}

The author would like to thank teachers and students for participating in the survey and focus group discussion. Also I thank the administration of schools for the permission to conduct the survey and interviews. I also would like to thank Mr. Damaru Ballabha Paudel, Ramhari Silwal 
and Takahiro Tsujimoto for their assistance while drafting this paper. I also thank Jeffrey Lee for his helpful comments while drafting the manuscript. Last but not the least, I also wish to thank three anonymous referees for their comments which helped improved the manuscript.

\section{References}

Adeyemi, T. O. (2009). Enrolment analysis and teacher requirements for the universal basic education programme in kwara state, Nigeria. Current Research Journal of Economic Theory, 1(1), 15-22.

Avramidis, E., Bayliss, P., \& Burden, R. (2000). A survey into mainstream teachers' attitudes towards the inclusion of children with special educational needs in the ordinary school in one local education authority. Educational psychology, 20(2), 191-211.

Berry, R. A. W. (2008). Novice teachers’ conceptions of fairness in inclusion classrooms. Teaching and Teacher Education, 24(5), 1149-1159.

CBS (Central Bureau of Statistics). (2012). National Population and Housing Census National Report. Kathmandu: Government of Nepal.

Cornoldi, C., Terreni, A., Scruggs, T. E., \& Mastropieri, M. A. (1998). Teacher Attitudes in Italy After Twenty Years of Inclusion. Remedial and Special Education 19, no. 6: 350-356.

Coskun, Y. D., Tosun, U., \& Macaroglu, E. (2009). Classroom Teachers Styles of Using and Development Materials of Inclusive Education. Online Submission,1, $2758-2762$.

Department of Education, Government of Nepal; www.doe.gov.np (Accessed $14^{\text {th }}$ Apr. 2016)

Deraniyagala, S. (2005). The political economy of civil conflict in Nepal. Oxford Development Studies, 33(1), 47-62. 
Eide, A. H., \& Loeb, M. E. (2005). Data and statistics on disability in developing countries. Disability Knowledge and Research Programme Executive Summary.

Elder, B. C., Damiani, M. L., \& Oswago, B. O. (2015). From attitudes to practice: utilising inclusive teaching strategies in Kenyan primary schools. International Journal of Inclusive Education, 1-22.

Graneheim, U. H., \& Lundman, B. (2004). Qualitative content analysis in nursing research: concepts, procedures and measures to achieve trustworthiness. Nurse education today, 24(2), 105-112.

Hall, A. (1990). Services to Blind Persons in Nepal: Issues Facing a Developing Country. Journal of Visual Impairment and Blindness, 84(6), 309-15.

Haskell, D. H. (2000). Building bridges between science and special education: inclusion in the science classroom. Electronic Journal of Science Education,4(3).

Heiman, T. (2001). Inclusive schooling-middle school teachers' perceptions.School Psychology International, 22(4), 451-462.

Johnson, R. B., Onwuegbuzie, A. J., \& Turner, L. A. (2007). Toward a definition of mixed methods research. Journal of mixed methods research, 1(2), 112133.

Lamichhane, K. (2010). A Comparative Study on Integrated Educational Facilities in Nepal. AER Journal: Research and Practice in Visual Impairment and Blindness 3, no. 2: 33-40.

Lamichhane, K. (2012). Employment situation and life changes for people with disabilities: evidence from Nepal. Disability \& Society, 27(4), 471-485.

Lamichhane, K. (2013). Disability and barriers to education: evidence from Nepal. Scandinavian Journal of Disability Research 15, no. 4: 311-324. 
Lamichhane, K. (2015). Disability, education and employment in developing countries: from charity to investment. Disability and Barriers to Education, 212-2119. Cambridge: Cambridge Univ. Press.

Lamichhane, K. (2012) Employment situation and life changes for people with disabilities: Evidence from Nepal, Disability and Society, 27 (4), pp. 471-485.

Lampropoulou, V., \& Padelliadu, S. (1997). Teachers of the Deaf as compared with other groups of Teachers : Attitudes toward people with disability and inclusion. American Annals of the Deaf 142, no. 1: 2633.

Lee, J. and Sparks, P. (2014). Sustaining a Nepali Telecenter: An Ethnographic Look Using Activity Theory. International Journal of Education and Development using Informtaion and Communication Technology 10 no. 2.

Minke, K. M., Bear, G. G., Deemer, S. A., \& Griffin, S. M. (1996). Teachers experiences with inclusive classrooms : implications for special education reforms. The Journal of Special Education 30, no.2: 152-186.

Mittler, P. (2012). Working towards inclusive education: Social contexts. Routledge.

O'Donoghue, T. A., \& Chalmers, R. (2000). How teachers manage their work in inclusive classrooms. Teaching and Teacher Education 16, no. 8: 889-904.

Patton, M. Q., (2015). Qualitative Research \& Evaluation Methods: Integrating Theory and Practice; Fourth Edition. SAGE Publications, Inc; Fourth Pryor, J., Akyeampong, K., Westbrook, J., \& Lussier, K. (2012). Rethinking teacher preparation and professional development in Africa: an analysis of the curriculum of teacher education in the teaching of early reading and mathematics. Curriculum Journal, 23(4), 409-502. 
Sapp, W., \& Hatlen, P. (2010). The expanded core curriculum: Where we have been, where we are going, and how we can get there. Journal of Visual Impairment \& Blindness, 104(6), 338.

Scott, B.J., Vitale, M.R. \& Masten, W.G. 1998. Implementing instructional adaptations for students with disabilities in inclusive classrooms: A literature review. Remedial and Special Education 19, no. 2, 106-119.

Subban, P., \& Sharma, U. 2005. Understanding Educator Attitudes Toward the Implementation of Inclusive Education. Disability Studies Quarterly, 25, no. 2 Available at: http://dsq-sds.org/article/view/545/722 (Accessed 20 January 2014).

UNESCO (1994) The Salamanca Statement and Framework for Action on Special Needs Education. World Conference on Special Needs Education: Access and Quality, Salamanca, Spain, 7-10 June 1994. Paris: UNESCO.

UNESCO. (2014). Teaching and Learning: Achieving quality for all. EFA GlobalMonitoring Report. Paris: UNESCO.

UNESCO. (2015). World Education Forum 2015 at: http://en.unesco.org/worldeducation-forum-2015/incheon-declaration (Accessed 7 Dec. 2015).

United Nations. 2006. UN Convention on the Rights of Persons with Disabilities. http://www.un.org/disabilities/convention/conventionfull.shtml. (Accessed 7 Dec. 2015) United Nations. (2015). Sustainable Development: Knowledge platform: SDGs \& Topics at: https://sustainabledevelopment.un.org/sdg4 (7 Dec. 2015) Unianu (2012). Teachers’ attitudes towards inclusive education. Procedia Social and Behavioral Sciences 33: 900 -9.

Van Reusen, A. K., Shoho, A. R., \& Barker, K. S. (2001). High School Teacher Attitudes toward Inclusion. The High School Journal 84, no. 2: 7-17. 
Westbrook, J., \& Croft, A. (2015). Beginning to teach inclusively: An analysis of newly-qualified teacher pedagogy in lower primary classes in Tanzania. Teaching and Teacher Education, 51, 38-46.

World Bank. (2014). World Bank Development Indicator - Nepal at: http://data.worldbank.org/country/nepal (Accessed 7 Dec. 2015) 